\title{
FONEMAS VOCÁLICOS DE PUERTO RICO \\ (Análisis acústico realizado con los materiales grabados para el estudio de la norma culta de San Juan) ${ }^{x}$
}

\author{
María Vaquero y Lourdes Guerra de la Fuente \\ Universidad de Puerto Rico
}

0.1. El español antillano cuenta, desde 1973, con estudios fonológicos modernos sobre los procesos de cambios consonánticos más caracterizadores de esta zona dialectal ${ }^{2}$, pero no podemos decir lo mismo respecto a los estudios del vocalismo, sobre el cual nos faltan estudios de valores en posición normal que permitan interpretar adecuadamente la variación ${ }^{3}$.

0.2. El caso del Caribe no es excepción, dentro de Hispanoamérica, donde no existen trabajos destinados a identificar valores fonológicos vocálicos, a partir de muestras de habla suficientemente amplias como para ofrecer un número considerable de realizaciones fonéticas, contextos lingüísticos y variables sociales 4 .

1 Esta investigación se llevó a cabo, en su primera etapa, mediante una ayudantía de investigación concedida por el Decanato de Asuntos Académicos del Recinto de Río Piedras de la Universidad de Puerto Rico, que se extendió desde enero de 1990 hasta agosto de 1991. La señorita Lourdes Guerra de la Fuente fue ayudante durante un año y la señorita Sunny Cabrera Salcedo durante seis meses. La señorita Guerra sobrepasó con creces su compromiso como ayudante convirtiéndose en coautora del trabajo.

Que conste mi gratitud: a las autoridades universitarias de Río Piedras, a las dos estudiosas citadas y a la acogida generosa que brinda a este trabajo la Revista de Filologia Española, en el número especial de 1992, dedicado al español de América.

2 Véase, sobre este punto: H. López Morales, «Caracterización fonológica de los dialectos del Caribe hispánico», Actas del I Congreso Internacional de Historia de la Lengua Española (Cáceres, 1987), eds. por M. Ariza, A. Salvador y A. Viudas. Madrid, Arco/Libros, 1990, págs. 1402-1415.

3 Véase: M. Vaquero. «Estudios fonológicos en Puerto Rico: revisión crítica», Voz y Letra, I, 1990, págs. 112-127, y «El español de Puerto Rico en su contexto antillano", El español de América, Actas del III Congreso Internacional sobre el español de América, I, eds. C. Hernández et al., Valladolid, Junta de Castilla y León, 1991, págs. 117-139.

4 Véase la relación crítica que hace Antonio Quilis (Fonética acústica de la lengua española, Madrid, Gredos, 1981, págs. 170-171) de los trabajos publicados sobre el 
0.3. De alcance general es el estudio que Antonio Quilis y Manuel Esgueva realizaron en $1983^{5}$. Su propósito era identificar las características acústicas de las realizaciones vocálicas del español en posición fonética nor$\mathrm{mal}^{6}$, a partir de treinta palabras incluidas en una frase portadora de significado, que veintidós informantes (siete hispanoamericanos y quince españoles; dieciséis hombres y seis mujeres) leyeron a un ritmo normal y con total naturalidad.

0.4. No hay duda de que, mediante la lectura de las palabras previamente seleccionadas, se garantiza la obtención de todas las realizaciones buscadas, lo cual permite calcular, sin casillas vacías, los valores medios de todas las unidades fonéticas, en relación con las variables y contextos que se tengan en cuenta. Esta es la razón de que Quilis y Esgueva puedan ofrecer el cuadro de valores acústicos más completo que tenemos de las realizaciones vocálicas españolas en las tres posiciones normales, correspondientes a los contextos p-p, b-b y m-m, cuadro y valores a los cuales habrá que seguir refiriéndose durante mucho tiempo.

0.5. Algo muy diferente ocurre cuando se parte de la lengua oral, pues, aunque se trabaje con muchas horas de grabación, es casi segura la ausencia de determinadas realizaciones. Si es cierto, por un lado, que contextos y realizaciones vocálicas tienen sus propias frecuencias de aparición, y que, en algunos casos, la probabilidad de realización se reduce al máximo, también es un hecho, por lo mismo, que, después de cierto número de horas, suele repetirse lo ya recogido, sin que aparezcan los datos necesarios para llenar las casillas vacías.

0.6. Ante estos hechos no hay más remedio que reconocer las limitaciones inherentes a ambos métodos de trabajo, así como sus ventajas particulares: la lectura de palabras garantiza la posibilidad de proyectar en las cartas formánticas los valores medios de todas las realizaciones, pero no asegura

español, desde el pionero de R. B. Skelton, A Spectrographic Analysis of Spanish Vowel Sounds, Ann Arbor, University Microfilms Abstracts, V, 10, 1950 (dedicado al análisis de vocales en palabras aisladas, sin llegar a resultados concretos), hasta el de Iraset Páez Urdaneta, *Apertura y cerrazón vocálicas en español: evidencia idiolectal», Letras (Caracas), 36, 1979, págs. 129-157, cuya muestra no «permite obtener conclusiones válidas».

- A. Quilis y M. Esgueva, «Realización de los fonemas vocálicos españoles en posición fonética normal», Estudios de fonética I, C. Ph. VII, Madrid, CSIC, 1983, págs. 159-252.

- «Una vocal se encuentra en posición fonética normal cuando está situada entre dos consonantes labiales. La consonante labial, por no ser lingual, no afecta a la articulación de la vocal, que es eminentemente lingual», A. Quilis, Fonética acústica, ya citado, pág. 159, nota 8 . 
el grado de espontaneidad conseguido en grabaciones libres; en este segundo caso, por su parte, la misma realidad del habla no favorece la obtención de todas las realizaciones teóricamente posibles.

0.7. Los estudios estadísticos hechos hace algunos años sobre las hablas de La Habana y San Juan para medir las realizaciones de la /s/ final de palabra ${ }^{7}$ motivaron, por un lado, la reconsideración, en estas hablas, de la hipótesis tradicional del desdoblamiento fonológico vocálico, en caso de ausencia de todo rastro fonético de dicho fonema final, y, por otro, favorecieron la aceptación de nuevas explicaciones en cuanto a las marcas morfémicas en la superficie ${ }^{8}$.

0.8. La polémica en torno a las consecuencias lingüísticas que pueda tener en el Caribe la pérdida de /s/ final necesita, para su definitiva superación, investigaciones científicas que ofrezcan, antes de nada, los valores fonológicos "normales" de las vocales en el español de la zona. Interpretar fonológicamente los timbres de las vocales que han quedado en posición final por pérdida de /s/ final morfémica, sin contar con las referencias normales correspondientes que den valor a estas realizaciones, no es camino seguro para llegar a conclusiones válidas, por más que la cuantificación de los datos y su tratamiento estadístico sean impecables. Por esta razón, y a pesar de las calas que ponen en duda el pretendido "desdoblamiento fonológico vocálico" ", es necesario obtener los valores normales que sirvan de referencia a futuras investigaciones de muestras más amplias y confiables.

0.9. Este trabajo, al presentar datos sobre valores normales de las vocales de Puerto Rico cuyas realizaciones ofrece la muestra analizada, intenta iniciar el estudio científico del vocalismo antillano, hoy por hoy conocido sólo intuitivamente.

0.10. El trabajo que aquí se ofrece parte de la lengua oral grabada y recogida para el estudio del habla culta de San Juan de Puerto Rico. La investigación, por lo tanto, se inscribe dentro del Proyecto de estudio del

7 A Tracy Terrell se debe la mayoria de estos trabajos, publicados entre 1975 y 1979. Véase, de M. Vaquero, «El español de Puerto Rico en su contexto antillano», ya citado, notas $40-48$.

8 Se desarrolló por esta época la llamada «hipótesis funcional», defendida por estudiosos de las hablas antillanas: cfr. H. López Morales, Estratificacion social en el español de San Juan de Puerto Rico, México, UNAM, 1983, pág. 47, y notas 11 y 12.

- El «desdoblamiento fonológico» sólo parece haberse aceptado en Puerto Rico, pues los estudiosos del español cubano y dominicano siempre han sido más cautelosos en este punto. Para detalles, véase: M. Vaquero, «El español de Puerto Rico en su contexto antillanow, ya citado, págs. 121-128. 
español hablado en las principales ciudades del mundo hispánico ${ }^{10}$, y es - hasta donde tenemos noticia - no sólo el único estudio fonológico-acústico de vocales realizado sobre estos materiales ", sino el primer análisis riguroso que se lleva a cabo, en español, a partir de una muestra tan amplia de lengua oral ${ }^{12}$. Las limitaciones impuestas por el mismo corpus, en cuanto a la imposibilidad de obtener todas las realizaciones necesarias, podrán subsanarse, en su día, con los análisis que hemos iniciado sobre las encuestas recogidas para el Atlas Lingüistico de las Antillas ${ }^{13}$, donde sí aparecen todos los contornos fonéticos necesarios.

1.1. Siguiendo el principio según el cual las vocales se encuentran en posición fonética normal cuando están situadas entre dos consonantes labiales ${ }^{14}$, se partió de treinta y cinco horas de habla, recogidas en la ciudad de San Juan para el estudio de la norma culta, y se identificaron, en dichas grabaciones, todas las realizaciones vocálicas tónicas y átonas en cada uno de los tres contextos posibles p-p, b-b y $\mathbf{m}-\mathbf{m} / \mathbf{n}$.

1.2. Las treinta y cinco horas de grabación sometidas al análisis acústico se distribuyen de acuerdo con los criterios seguidos por el ya citado Proyecto del PILEI ${ }^{15}$, de cuyos materiales hemos partido para realizar los análisis. Las horas y encuestas disponibles, tanto publicadas ${ }^{16}$ como sin publicar, teniendo en cuenta las variables de Generación y Sexo especificadas en el Proyecto, aparecen detalladas en el cuadro siguiente.

10 Para todo lo relacionado con este Proyecto internacional, véase: Juan M. Lope Blanch, El estudio del español bablado culto. Historia de un proyecto, México, UNAM, 1986.

11 Véanse: Juan M. Lope Blanch, Estudio sobre el español hablado en las principales ciudades de América, México, UNAM, 1977; M. Vaquero, «El español de América, el español de Puerto Rico y dos proyectos de estudio: El español culto de las capitales y el Atlas Lingülstico de Hispanoamérica», Asomante 1-2, 1989, págs. 11-28. Juan M. Lope Blanch prepara en este momento un volumen que hace relación de todos los trabajos hechos desde 1968, comienzo de estas investigaciones, hasta 1992.

13 El trabajo de Manuel Almeida, «El timbre vocálico en español actual», publicado en Filología Románica 7, 1990, págs. 75-85, a pesar del título, se limita al español de Canarias. Es lástima, por otra parte, que sus análisis y cómputos acústicos, realizados a partir de «unas 1.500 vocales estudiadas» (pág. 79), se presenten de forma tan general y selectiva, por lo cual, y mientras no se publique la totalidad de los datos obtenidos, con la interrelación explícita de los factores manejados, estas páginas pueden considerarse como anticipo del trabajo completo y promesa que, sin duda, cumplirá su autor, para beneficio de todos.

13 Primer volumen del Atlas Lingüistico de Hispanoamérica, dirigido por M. Alvar, volumen de inminente aparición.

14 Véase nota 4.

15 Véase nota 11.

16 A. Morales y M. Vaquero, El babla culta de San Juan. Materiales para su estudio, San Juan, Editorial de la Universidad de Puerto Rico, 1989. 


\section{CUADRO 1}

Total de horas (H) y encuestas analizadas (E), tenlendo en cuenta las variables de Generacion y Sexo.

\begin{tabular}{|c|c|c|c|c|c|c|c|c|c|}
\hline \multirow{2}{*}{\multicolumn{2}{|c|}{$\begin{array}{l}\text { Generacion ... } \\
\text { Sexo ......... }\end{array}$}} & \multicolumn{2}{|c|}{ I } & \multicolumn{2}{|c|}{ II } & \multicolumn{2}{|c|}{ III } & \multicolumn{2}{|c|}{ TOTAL } \\
\hline & & $\mathbf{M}$ & $\mathbf{F}$ & $\mathbf{M}$ & $\mathbf{F}$ & $\mathbf{M}$ & $\mathbf{F}$ & H & $\mathbf{E}$ \\
\hline \multirow{6}{*}{\multicolumn{2}{|c|}{$\begin{array}{l}\text { Materiales } \\
\text { publicados }\end{array}$}} & $4 \mathrm{AB}^{17}$ & $20 \mathrm{~A}$ & $1 \mathrm{~A}$ & $9 \mathrm{AB}$ & $13 \mathrm{AB}$ & $33 \mathrm{AB}$ & 5 & 6 \\
\hline & & $6 \mathrm{AB}$ & $38 \mathrm{~A}$ & $2 \mathrm{AB}$ & $16 \mathrm{AB}$ & $40 \mathrm{~A}$ & & 4 & 5 \\
\hline & & $7 \mathrm{AB}$ & $39 \mathrm{~A}$ & $3 \mathrm{AB}$ & $21 \mathrm{AB}$ & $42 \mathrm{~A}$ & & 4 & 5 \\
\hline & & $22 \mathrm{AB}$ & & $12 \mathrm{AB}$ & $25 \mathrm{AB}$ & & & 3 & 3 \\
\hline & & & & $19 \mathrm{~A}$ & $44 \mathrm{AB}$ & & & 1.5 & 2 \\
\hline & & & & $24 \mathrm{~A}$ & & & & 0.5 & 1 \\
\hline \multirow{9}{*}{\multicolumn{2}{|c|}{$\begin{array}{l}\text { Materlales } \\
\text { sin } \\
\text { publicar }\end{array}$}} & $5 \mathrm{AB}$ & $18 \mathrm{AB}$ & $1 \mathrm{~B}$ & $11 \mathrm{AB}$ & $10 \mathrm{AB}$ & $49 \mathrm{AB}$ & 5.5 & 5 \\
\hline & & $32 \mathrm{AB}$ & $20 \mathrm{~B}$ & $8 \mathrm{AB}$ & & $53 \mathrm{~B}$ & $51 \mathrm{~A}$ & 3.5 & 4 \\
\hline & & $36 \mathrm{AB}$ & $37 \mathrm{AB}$ & $23 \mathrm{~A}$ & & & $52 \mathrm{~A}$ & 3 & 4 \\
\hline & & & 38 B & $24 \mathrm{BC}^{18}$ & & & & 1.5 & 0 \\
\hline & & & $43 \mathrm{~A}$ & $27 \mathrm{AB}$ & & & & 1.5 & 2 \\
\hline & & & & $29 \mathrm{~A}$ & & & & 5 & 1 \\
\hline & & & & $31 \mathrm{~A}$ & & & & 5 & 1 \\
\hline & & & & $34 \mathrm{~A}$ & & & & 5 & 1 \\
\hline & & & & $35 \mathrm{~B}$ & & & & 5 & 1 \\
\hline \multirow{2}{*}{ TOTAL } & $\mathbf{H}$ & 7 & 5 & 10.5 & 6 & 3.5 & 3 & 35 & \\
\hline & $\mathbf{E}$ & 7 & 6 & 13 & 6 & 5 & 4 & & 41 \\
\hline
\end{tabular}

1.3. En el total de treinta y cinco horas y 41 encuestas, las realizaciones vocálicas recogidas y analizadas en los tres contextos considerados suman un total de $1446^{19}$, de las cuales casi las tres cuartas partes $(72.13 \%)$ perte-

17 Cada una de las encuestas de la muestra se identifica aqui con el número que le corresponde en el archivo, seguido de una o dos letras mayúsculas, correspondientes a «primera media hora de grabación: A» y «segunda media hora de grabación: B». Esto significa, a) que el total de encuestas es el total de informantes, b) que algunas encuestas son de una hora, y otras de media hora, c) que, en algunos casos, la primera media hora de una encuesta está publicada y la segunda no, o al contrario, y d) que, en este último caso, se repite el número identificador de la encuesta, pero lógicamente sólo se cuenta la primera vez.

18 La encuesta 24 corresponde a un informante masculino de la segunda generación cuya grabación duró una hora y media; la primera media hora, A, está publicada (op. cit., págs. 259-268), y la hora restante, que se identifica BC, está sin publicar.

10 Se habfan obtenido 1.500 realizaciones vocálicas, pero, de los 1.500 espectros realizados, se rechazaron 54 por presentar dificultades que hacian imposible la medición, como interferencias y rapidez excesiva en el habla. 
necen al contexto nasal. El cuadro 2 presenta la distribución de estas realizaciones teniendo en cuenta contextos y variables.

\section{Cundro 2}

Reallzaciones y expectros medidos, tenlendo en cuenta los tres contextos y las dos variables.

\begin{tabular}{|c|c|c|c|c|c|c|c|c|c|}
\hline \multicolumn{2}{|c|}{ Contextos } & \multirow{2}{*}{\multicolumn{2}{|c|}{$\mathbf{p} \cdot \mathbf{p}$}} & \multirow{2}{*}{\multicolumn{2}{|c|}{$\mathbf{b} \cdot \mathbf{b}$}} & \multirow{2}{*}{\multicolumn{2}{|c|}{$\mathbf{m} \cdot \mathbf{m} / \mathbf{n}$}} & \multirow{2}{*}{\multicolumn{2}{|c|}{ TOTAL }} \\
\hline Generacłon & Sexo & & & & & & & & \\
\hline \multirow{3}{*}{ I } & $\mathbf{M}$ & & 24 & & 59 & & 288 & & 371 \\
\hline & & 38 & & 105 & & 412 & & 555 & \\
\hline & $\mathbf{F}$ & & & & 46 & & 124 & & 184 \\
\hline \multirow{3}{*}{ II } & M & & 34 & & 93 & & 336 & & 463 \\
\hline & & 50 & & 134 & & 444 & & 628 & \\
\hline & $\mathbf{F}$ & & 16 & & 41 & & 108 & & 165 \\
\hline \multirow{3}{*}{ III } & M & & 9 & & 39 & & 125 & & 173 \\
\hline & & 20 & & 36 & & 187 & & 263 & \\
\hline & $\mathbf{F}$ & & 11 & & 17 & & 62 & & 90 \\
\hline \multirow{3}{*}{ TOTAL } & $\mathbf{M}$ & & 67 & & 191 & & 749 & & 1007 \\
\hline & & 108 & & 293 & & 1043 & & 1446 & \\
\hline & $\mathbf{F}$ & & 41 & & 104 & & 294 & & 439 \\
\hline
\end{tabular}

1.4. El cuadro 2 demuestra claramente el desequilibrio entre el número de realizaciones vocálicas recogidas en los contextos orales, muy poco favorecidos, y el contexto nasal. El cuadro 3 ofrece el número de realizaciones tónicas y átonas de cada vocal en cada contexto, con la evidencia de muchas casillas vacias en los dos orales y, en algunos casos, una sola realización, todo lo cual elimina la posibilidad de obtener valores medios de las diez unidades en dichos contextos. Ante los datos obtenidos, y aunque se midieron los 1446 espectros, para el presente trabajo se tuvieron en cuenta solamente los 1043 correspondientes al contexto nasal $\mathbf{m} \cdot \mathbf{m} / \mathbf{n}^{20}$.

20 En este contexto sólo aparece una casilla vacía, correspondiente a la [1] en las mujeres de la tercera generación, de la cual no fue posible obtener realización alguna en la muestra. 
Cuadro 3

Reallzaciones vocallicas tónicas y átonas en los tres contextos, en relación con las variables consideradas.

\begin{tabular}{|c|c|c|c|c|c|c|c|c|}
\hline \multirow{2}{*}{\multicolumn{2}{|c|}{$\frac{\text { Generaclón } \ldots \ldots \ldots \ldots}{\text { Sexo } . \ldots \ldots \ldots \ldots}$}} & \multicolumn{2}{|c|}{ I } & \multicolumn{2}{|c|}{ II } & \multicolumn{2}{|c|}{ III } & \multirow{2}{*}{ TOTAL } \\
\hline & & $\mathbf{M}$ & $\mathbf{F}$ & $\mathbf{M}$ & $\mathbf{F}$ & M & $\mathbf{F}$ & \\
\hline \multirow[t]{5}{*}{ Contextos } & Vocales & & & & & & & \\
\hline & [1] & & & & & & & \\
\hline & [1] & 1 & & & & & & 1 \\
\hline & [é] & & & 2 & & & & 2 \\
\hline & [e] & & & & & 3 & & 3 \\
\hline \multirow{10}{*}{$\mathbf{p} \cdot \mathbf{p}$} & [a] & 6 & 2 & 1 & 2 & & & 11 \\
\hline & [a] & 12 & 9 & 20 & 13 & 4 & 11 & 69 \\
\hline & [6] & & & & & & & \\
\hline & [o] & 5 & 3 & 11 & 1 & 2 & & 22 \\
\hline & [ư] & & & & & & & \\
\hline & [u] & & & & & & & \\
\hline & [1] & 16 & 1 & 28 & 11 & 5 & 4 & 65 \\
\hline & [1] & 21 & 23 & 44 & 17 & 26 & 11 & 142 \\
\hline & [6] & & & 1 & 1 & & 1 & 3 \\
\hline & [e] & 1 & & 2 & 1 & & & 4 \\
\hline \multirow[t]{2}{*}{$\mathbf{b} \cdot \mathbf{b}$} & [ád] & 11 & 9 & 11 & 4 & 7 & & 42 \\
\hline & [a] & 9 & 4 & 7 & 4 & 1 & 1 & 26 \\
\hline & [6] & & 7 & & & & & 7 \\
\hline \multirow[t]{7}{*}{. } & [o] & 1 & 2 & & 3 & & & 6 \\
\hline & [ú] & & & & & & & \\
\hline & [u] & & & & & & & \\
\hline & [1] & 23 & 12 & 7 & 14 & 7 & 2 & 65 \\
\hline & [1] & 3 & 5 & 4 & 6 & 4 & [ ] & 22 \\
\hline & [6] & 87 & 25 & 78 & 24 & 23 & 18 & 255 \\
\hline & [ब] & 7 & 11 & 19 & 8 & 3 & 4 & 52 \\
\hline \multirow[t]{6}{*}{$\mathbf{m} \cdot \mathbf{m} / \mathbf{n}$} & [6] & 3 & 3 & 14 & 2 & 2 & 2 & 26 \\
\hline & [a] & 25 & 14 & 26 & 9 & 11 & 11 & 9 \\
\hline & [6] & 10 & 10 & 27 & 2 & 10 & 3 & 62 \\
\hline & [0] & 71 & 24 & 46 & 18 & 16 & 9 & 184 \\
\hline & [ü] & 39 & 12 & 44 & 19 & 25 & 7 & 146 \\
\hline & [u] & 20 & 8 & 71 & 6 & 24 & 6 & 135 \\
\hline \multicolumn{2}{|l|}{ TOTAL . . } & 371 & 184 & 463 & 165 & 173 & 90 & 1446 \\
\hline
\end{tabular}


2.1. Las variantes tónicas $\mathrm{y}$ átonas recogidas en el contexto nasal aparecieron en las siguientes palabras o secuencias ${ }^{21}$ :

[1] a mi me, a mi mismo, de mi más, pantomima,

[1] mi madre, mi mamá, mi mar, mi memoria, mi mente, mi mentor, mi modo, mimeógrafo, Tomy Muñiz,

[é] actualmente ${ }^{22}$, continuamente, definitivamente, directamente, documento $(s)$, especialmentc, indiscutiblemente, inmediatamente, intimamente, libérrimamente, llamemos, malamente, mente, momento(s), monumentos, originalmente, principalmente, próximamente, puramente, realmente, sencillamente, solamente, sumamente, totalmente, tremenda, últimamente, unánimemente, vulgarmente.

[e] bidimensional, comprarme mis, come muy, me mandaban, me mandaron, me mata, me matriculaba, me matriculará, me matriculé, me matriculo, me meti, me metieron, me molesta, me molestaba, me montaron, me mortifica, me mudé, me muevo, membresia, memorable, memorandos, memorandum, memoria, memorial, memoriza, memorizar, mentor, momentito, tome más, unánimemente,

[á] alarmamos, estimamos, firmamos, llamamos, mamá me, sumamos, tomamos,

[a] alma mater, armamentos, encima muy, forma más, forma minima, idioma menospreciado, intimamente, libérrimamente, llama mayor, llama muchísimo, llama mucho, mamá(s), mamotreto, mandaron, misma marca, misma medida, misma muchacha, problema más, problema mayor, problema muy; próximamente, sumamente, toma más, toma muchísimo, últimamente, última moda,

[б] Bayamón, desmonte, llamó muchisimo, momia, Momo, Mónaco, monta(n), monte(s), monto, pintamonas, Ramón, Salomón, termómètro,

[o] como maestra, cómo manejar, como Maquiavelo, como marxista, como me, como mediadora, como medida, como medio, como Mesopotamia, como meta, como métodos, como mi, como minimo, como muchos, como murió, como museo, cubismo mismo, intimo mio, minimo movimiento, mismo

21 Muchas de estas palabras y secuencias aparecieron reiteradamente en los 41 informantes; sobresalen por su frecuencia: como (en construcciones comparativas), común, comunicar y sus derivados, documento, momento, mundo, y los adverbios en -mente.

a En la mayoría de los casos, estos adverbios se pronuncian con un solo acento en [-mente]. 
medio, mismo momento, mismo Muñoz, momento(s), Montañez, montar, montaron, último momento,

[ú] comun(es), comúnmente, mundo, Unamuno,

[u] comunal, comunicación(es), comunican, comunicar, comunicarme, comunicarse, comunicárselo, comunico, comunidad(es), comuniqué, comunista(s), comunitaria, mundial(es), municipal(es), municipio(s), remuneración, unamunesca, unamunescos.

2.2. Los análisis acústicos se hicieron en el Instituto de Lingüística de la Universidad de Puerto Rico, mediante el "Digital Sona Graph, Modelo 7800" de la Kay Electric Co. Los valores buscados, para cada una de las 1.043 realizaciones vocálicas previamente identificadas y analizadas, fueron: el primero (F1), el segundo (F2) y, cuando era posible, el tercer (F3) formantes. También se obtuvo la duración $(\mathrm{T})$ de cada realización. A continuación se ofrecen todos los datos, de lo particular a lo general, que permiten trazar, para el contexto considerado:

1. Los triángulos acústicos vocálicos en relación con las variables consideradas, Generación y Sexo.

2. Los triángulos acústicos de las realizaciones vocálicas tónicas $\mathrm{y}$ átonas en relación con los informantes femeninos y masculinos.

3. Un triángulo acústico de los fonemas vocálicos de Puerto Rico en el contexto oronasal.

3.1. Los cuadros 4,5 y 6 ofrecen los valores de los dos primeros formantes de los fonemas y sus realizaciones tónicas/átonas, en relación con las generaciones primera, segunda y tercera, respectivamente. Las figuras 1, 2 y 3 ofrecen, para cada una de las tres generaciones respectivamente, los triángulos de vocales tónicas y átonas. La figura 4 presenta los triángulos vocálicos por generación. 


\section{Cundro 4}

Primera generación: fonemas y realizaciones tónicas/atonas.

\begin{tabular}{|c|c|c|c|}
\hline & F1 & F2 & $\mathbf{T}$ \\
\hline [1] (35) & 445.2 & 2255 & 8 \\
\hline [1] (8) & 510.8 & 2396 & 7.3 \\
\hline /1/ (43) & 478 & 2325.7 & 7.5 \\
\hline [é] (112) & 590.7 & 2011.2 & 9 \\
\hline [e] (18) & 590 & 1778.7 & 8 \\
\hline /e/ (130) & 590 & 1894.9 & 8.6 \\
\hline [d] (6) & 777.4 & 1291.1 & 9.5 \\
\hline [a] (39) & 722.4 & 1315 & 8.4 \\
\hline /a/ (45) & 750 & 1303 & 9 \\
\hline [6] (20) & 587.2 & 927 & 11.5 \\
\hline [0] (95) & 560.4 & 880 & 8 \\
\hline$/ 0 /(115)$ & 573.9 & 903.3 & 9.8 \\
\hline [ú] (51) & 419.5 & 722 & 8.5 \\
\hline [u] (28) & 393 & 687.2 & 6.5 \\
\hline$/ \mathbf{u} /(79)$ & 406.2 & 704.7 & 7 \\
\hline
\end{tabular}

Cundro 5

Segunda generacion: fonemas y realizaciones tónicas y atonas.

\begin{tabular}{|c|c|c|c|}
\hline & F1 & F2 & $\mathbf{T}$ \\
\hline [1] (21) & 391.1 & 2222.3 & 7 \\
\hline [1] (10) & 399.1 & 2339.3 & 7.3 \\
\hline /1/ (31) & 395 & 2280.7 & 7.1 \\
\hline [6] (102) & 612.8 & 1916.3 & 8.6 \\
\hline [e] (27) & 600.8 & 1780.2 & 8 \\
\hline /e/ (129) & 606.8 & 1848.2 & 8.1 \\
\hline [a] (16) & 739.2 & 1220 & 9.3 \\
\hline [a] (35) & 735.3 & 1296.7 & 8.1 \\
\hline /a/ (51) & 737.2 & 1258.2 & 9 \\
\hline [6] (29) & 513.2 & 849.5 & 13.7 \\
\hline [o] (64) & 594 & 940.2 & 8 \\
\hline /o/ (93) & 553.5 & 894.8 & 10.8 \\
\hline [u] (63) & 376.4 & 680.1 & 9.2 \\
\hline [u] $(77)$ & 337.5 & 626.7 & 6 \\
\hline$/ \mathbf{u} /(140)$ & 357 & 653.4 & 7.5 \\
\hline
\end{tabular}


Cundro 6

Tercera generación: fonemas y realizaciones tónicas y átonas.

\begin{tabular}{|c|c|c|c|}
\hline & F1 & F2 & $T$ \\
\hline [1] (9) & 461 & 2121.1 & 7.7 \\
\hline \multicolumn{4}{|c|}{ [1] (no se sacan valores medios porque no hay en mujeres } \\
\hline \multicolumn{4}{|c|}{ /1/ (no se sacan valores medios) } \\
\hline [é] (41) & 582 & 1785 & 8.6 \\
\hline [e] (7) & 590 & 1752.7 & 9.8 \\
\hline /e/ (48) & 586 & 1769 & 9.2 \\
\hline [a] (4) & 728.8 & 1374.4 & 8.5 \\
\hline [a] (22) & 747.7 & 1364.9 & 9.6 \\
\hline /a/ (26) & 738.2 & 1369.6 & 9 \\
\hline [0] (13) & 608 & 951.7 & 9.2 \\
\hline [0] (25) & 578.1 & 906.1 & 7.3 \\
\hline$/ 0 /(38)$ & 593 & 929 & 8.2 \\
\hline [u] (32) & 393 & 673.5 & 9.2 \\
\hline [u] (30) & 349.6 & 636.8 & 6.2 \\
\hline$/ \mathbf{u} /(62)$ & 371.3 & 655.1 & 8 \\
\hline
\end{tabular}

CUndro 7

Hombres: fonemas y realizaciones tónicas y átonas.

\begin{tabular}{|c|c|c|c|}
\hline & F1 & F2 & $\mathbf{T}$ \\
\hline [1] (37) & 457.1 & 2124.4 & 6.8 \\
\hline [1] (11) & 480 & 2223.6 & 6.6 \\
\hline /1/ (48) & 468.5 & 2173.9 & 6.7 \\
\hline [é] (188) & 555.6 & 1756.4 & 8.1 \\
\hline [e] (29) & 535.6 & 1743 & 7.8 \\
\hline$/ e /(217)$ & 545.6 & 1749.7 & 7.9 \\
\hline [á] (19) & 687.2 & 1188 & 7.2 \\
\hline [a] (62) & 667.8 & 1250.9 & 8.5 \\
\hline$/ a /(81)$ & 677.5 & 1219.4 & 7.8 \\
\hline [6] (47) & 528.2 & 859.3 & 10.2 \\
\hline [o] (133) & 529.2 & 863.6 & 7.4 \\
\hline$/ 0 /(180)$ & 528.7 & 861.4 & 8.8 \\
\hline [ú] (108) & 396.6 & 688.8 & 8.2 \\
\hline [u] (115) & 384.1 & 687.4 & 6 \\
\hline$/ \mathbf{u} /(223)$ & 390.4 & 688.1 & 7.1 \\
\hline
\end{tabular}


3.2. Los cuadros 7 y 8 ofrecen los valores medios de los dos primeros formantes de los fonemas y de sus realizaciones tónicas y átonas, en relación, respectivamente, con los hombres y mujeres de la muestra. Las figuras 5, 6 y 7 presentan los triángulos acústicos vocálicos en hombres y mujeres, teniendo en cuenta la generación. Las figuras 8 y 9 presentan, respectivamente en hombres y mujeres, las realizaciones tónicas y átonas. Los triángulos vocálicos en hombres y mujeres aparecen en la figura 10.

Cundro 8

Mujeres: fonemas y realizaciones tónicas y átonas.

\begin{tabular}{|c|c|c|c|}
\hline & F1 & F2 & $\mathrm{T}$ \\
\hline [1] (28) & 407.8 & 2274.9 & 8.3 \\
\hline [1] (11) & 382.4 & 2545.4 & 8.2 \\
\hline /1/ (37) & 382.6 & 2468.6 & 8.2 \\
\hline [é] (67) & 634.7 & 2052 & 9.4 \\
\hline [e] (23) & 651.5 & 1798.2 & 9.3 \\
\hline$/ \mathrm{e} /(90)$ & 643.1 & 1925 & 9.3 \\
\hline [a] (7) & 809.8 & 1402.2 & 11.1 \\
\hline [a] (34) & 802.5 & 1400.2 & 9 \\
\hline /a/ (41) & 806.1 & 1401.2 & 10 \\
\hline [6] (15) & 610.8 & 959.3 & 12.9 \\
\hline [0] (51) & 625.7 & 953.9 & 8.2 \\
\hline$/ 0 /(66)$ & 618.2 & 956.6 & 10.5 \\
\hline [u] (38) & 396 & 695.2 & 9.8 \\
\hline [u] (20) & 336.1 & 613.1 & 6.4 \\
\hline$/ \mathbf{u} /(58)$ & 366 & 654.1 & 8.1 \\
\hline
\end{tabular}

3.3. El cuadro 9 ofrece los valores medios de los dos primeros formantes, y de la duración, de cada unidad vocálica y sus realizaciones tónicas y átonas. La figura 11 presenta los triángulos acústicos correspondientes a las vocales tónicas y átonas de la muestra, y la figura 12 ofrece un triángulo acústico de vocales en el español de Puerto Rico. 


\section{Cundro 9}

Vocales de la muestra y realizaclones tónicas y atonas: número de unidades 23 y valores medios totales de formantes y duraclones.

\begin{tabular}{|c|c|c|c|}
\hline & F1 & F2 & $\mathbf{T}$ \\
\hline [1] (65) & 432.5 & 2199.6 & 7.5 \\
\hline [1] (22) & 441 & 2352.3 & 7.2 \\
\hline /1/ $(85)^{24}$ & 434.2 & 2291.8 & 7.3 \\
\hline [é] (255) & 595.1 & 1904.2 & 8.7 \\
\hline [e] (52) & 593.5 & 1770.6 & 8.6 \\
\hline /e/ (307) & 594.3 & 1837.3 & 8.6 \\
\hline [á] (26) & 748.5 & 1295.1 & 9.1 \\
\hline [a] (96) & 735.2 & 1325.6 & 8.7 \\
\hline /a/ (122) & 741.8 & 1310.3 & 8.9 \\
\hline [6] (62) & 369.5 & 909.3 & 11.5 \\
\hline [0] (184) & 577.4 & 908.7 & 7.8 \\
\hline$/ 0 /(246)$ & 573.4 & 909 & 9.6 \\
\hline [ú] (146) & 396.3 & 692 & 9 \\
\hline [u] (135) & 360.1 & 650.2 & 6.2 \\
\hline /u/ (281) & 378.2 & 671.1 & 7.6 \\
\hline
\end{tabular}

\section{Conclusiones.}

\subsection{Duración.}

4.11. Los datos obtenidos demuestran que la vocal /o/ es la más larga, con $9.6 \mathrm{c} / \mathrm{s}$., dentro de la tendencia a la duración que demuestran todas las demás vocales; en este patrón durativo, las más breves son las dos vocales altas $/ \mathrm{i}$, u/, con 7.3 y $7.6 \mathrm{c} / \mathrm{s}$., respectivamente.

4.12. Son más largas las tónicas que las átonas: la duración media de las tónicas es de $9.16 \mathrm{y}$ la de las átonas es de $7.7 \mathrm{c} / \mathrm{s}$.

23 Entre paréntesis.

24 Como no se pueden sacar medias de [1] átona para las mujeres de la tercera generación, puesto que no apareció ninguna realización en este caso, se prescinde de las dos realizaciones tónicas de mujeres de la tercera, por lo cual los valores medios de /1/ se calculan sobre 85 unidades. Esto explica que, en las figuras 3,4 y 7 no se ofrezca el punto correspondiente a la vocal átona [1] en la tercera generación. 
4.13. La variable generación no altera la relación general durativa entre tónicas y átonas, pues, en las tres generaciones, las tónicas siguen siendo más largas, si bien la diferencia mínima de duración entre tónicas y átonas de la tercera permite contrastarla con las dos generaciones jóvenes, contraste que hace posible observar diferencias significativas. Las duraciones medias al respecto son las siguientes:

\begin{tabular}{|c|c|c|}
\hline & En tónicas & En átonas \\
\hline I & 9.3 c. s. & $7.6 \mathrm{cs} s$. \\
\hline II & $9.6 \mathrm{c.s}$. & 7.5 c. s. \\
\hline III & 8.6 c. s. & 8.2 c. s. \\
\hline
\end{tabular}

4.14. Tampoco la variable sexo altera la tendencia de las tónicas a ser más largas, pero la diferencia de duración entre tónicas y átonas se acusa en las mujeres. Existen diferencias significativas entre las duraciones masculinas, más breves, y las femeninas, más largas. Los valores medios son los siguientes:

\begin{tabular}{lrrrr} 
& \multicolumn{2}{c}{ En tónicas } & & En átonas \\
\cline { 2 - 2 } M & 8.1 c.s. & & 7.26 c.s. \\
F & 10.3 c.s. & & 8.22 c.s.
\end{tabular}

4.15. Si tomamos los datos ofrecidos por Quilis y Esgueva ${ }^{25}$ sobre las duraciones vocálicas de sus informantes en el contexto oronasal, podemos aceptar, al hacer la comparación correspondiente, que los informantes puertorriqueños manifiestan una duración de las vocales considerablemente mayor: frente al valor medio ofrecido por los autores citados de 5.57 c. s., nuestros datos arrojan una duración media en Puerto Rico de 8.4 c. s. Estos mismos autores especifican que, en general, la duración vocálica es mayor en los informantes hispanoamericanos de su muestra que en los españoles ${ }^{26}$; nuestros datos de Puerto Rico pueden corroborar esta conclusión en relación con el contexto oronasal.

4.16. Si tenemos en cuenta que las vocales puertorriqueñas se destacan por su larga duración en posición normal oronasal, habrá que interpretar con suma cautela cualquier tipo del llamado alargamiento vocálico en el español de Puerto Rico. Aunque es un hecho que nos faltan los datos relativos a los demás contextos "normales" ( $\mathrm{p}-\mathrm{p}$ y b-b), los datos que aquí ofrecemos prueban que no se puede seguir atribuyendo valor distintivo, de forma ca-

\footnotetext{
28 Op. cit., pág. 243.

26 Seis hombres (cuatro mexicanos, un ecuatoriano, un chileno) y una mujer, argentina.
} 
tegórica, a hechos aislados de evidente duración vocálica que pueden corresponder a comportamientos normales de habla. $\mathrm{Si}$, por otra parte, los experimentos acústicos de Quilis y Esgueva prueban que la duración de las vocales hispanoamericanas es mayor que la de las peninsulares, los nuestros ponen sobre el tapete el hecho de que las vocales puertorriqueñas, dentro del patrón hispanoamericano, pueden extremar la duración.

4.17. Aunque la comparación de nuestros datos con los de Quilis y Esgueva sólo puede ser aproximada, puesto que nuestros datos sólo se refieren al contexto oronasal, podemos decir:

1. Que en ambos estudios la duración de las tónicas es mayor que la duración de las átonas, por lo que esta tendencia general se ha probado experimentalmente en el español de Puerto Rico.

2. Que, de acuerdo con los datos allegados sobre los informantes hispanoamericanos (con duraciones mayores de las tónicas, respecto a los informantes españoles: 6.47 frente a 5.8 c. s.) la duración que manifiestan las vocales puertorriqueñas en nuestros análisis parece seguir el patrón caracteristico del español de América, patrón que habrá que usar como referencia en toda interpratación regional al respecto.

\subsection{Frecuencias de los formantes.}

4.21. Es evidente que las vocales cle nuestra muestra son mucho más abiertas de lo que cabría esperar. En relación con los triángulos acústicos que pueden servir de referencia, todas nuestras figuras muestran triángulos acústicos desplazados en su conjunto hacia la parte baja de las cartas formánticas, lo cual está en proporción directa con la abertura articulatoria total de las unidades ${ }^{2}$.

4.22. El triángulo de la figura 12 muestra una vocal extrema /u/ de articulación más cerrada que la /i/. Esto hace que el triángulo vocálico de Puerto Rico ofrezca una figura irregular, con asimetrías marcadas en los puntos de coordenadas de /i/ y / $/$ /. presentes también en las vocales /e/

27 «Las realizaciones vocálicas están representadas en la carta [logarítmica] de formantes por los puntos de coordenadas, de tal modo que en el eje de ordenadas se sitúa el valor del primer formante, y en el de abscisas, el valor del segundo formante. La situación del punto vocálico proporciona la siguiente información: cuanto más a la izquierda de la carta esté situado, tanto más anterior es la realización vocálica y viceversa. Cuanto más bajo esté situado, tanto más abierta es la vocal, y viceversa» (Quilis y Esgueva, op. cit., pág. 163). 
y $/ \mathrm{o} /$, aunque en estas últimas de forma menos acusada. En este triángulo, la vocal /a/ es marcadamente central, sin desplazamientos del segundo formante, a derecha o izquierda, que indiquen articulaciones palatales o velares de la $/ a /$.

4.23. La superposición de los triángulos oronasales de nuestros informantes masculinos - línea discontinua - y de los femeninos - linea continua-, de la figura 10, manifiesta resultados análogos a los que se ofrecen para el español general ${ }^{28}$, en el hecho de que, también en nuestros datos, son mayores las distancias que se producen en los informantes femeninos que en los masculinos, lo cual significa que nuestros informantes masculinos también articulan las vocales de forma más relajada, además de pronunciar la vocal /a/ ligeramente posterior respecto a la de las mujeres.

4.24. Asinismo, la superposición de los triángulos masculinos y femeninos de vocales tónicas, figura $8, y$ átonas, figura 9 , manifiesta en los hombres una distancia menor entre todas las vocales que en las mujeres; en estas últimas, las vocales son más nitidas: la distancia mayor se produce entre las vocales altas /i/, / $1 /$ y el resto. Se mantiene en los hombres la velarización de la /a/, todo ello más acusado en el caso de las tónicas.

4.25. El patrón citado del comportamiento femenino/masculino vuelve a aparecer, en general, cuando se superponen los clos triángulos correspondientes a cada una de las tres generaciones, sol)re todo en la seguncla (figuras 5, 6 y 7).

4.26. En cuanto al comportaniento vocálico de las tres generaciones, la segunda ofrece un triángulo más simétrico y centrado, como se desprencle de las figuras 1,2 y 3.

4.27. Las conclusiones más importantes de este estudio son las siguientes:

1. Las vocales de Puerto Rico tienden a ser más abiertas, en comparación con los grados generales de abertura en el español general.

2. La duración țambién es mayor, tanto en las realizaciones tónicas como en las átonas.

3.. La articulación, con velarización masculina de la /a/. es más relajada en los hombres que en las nujeres.

Rio Piedras, mayo de 1992.

28 Quilis y Esgueva, op. cit., pág. 245; y fig. 2. 


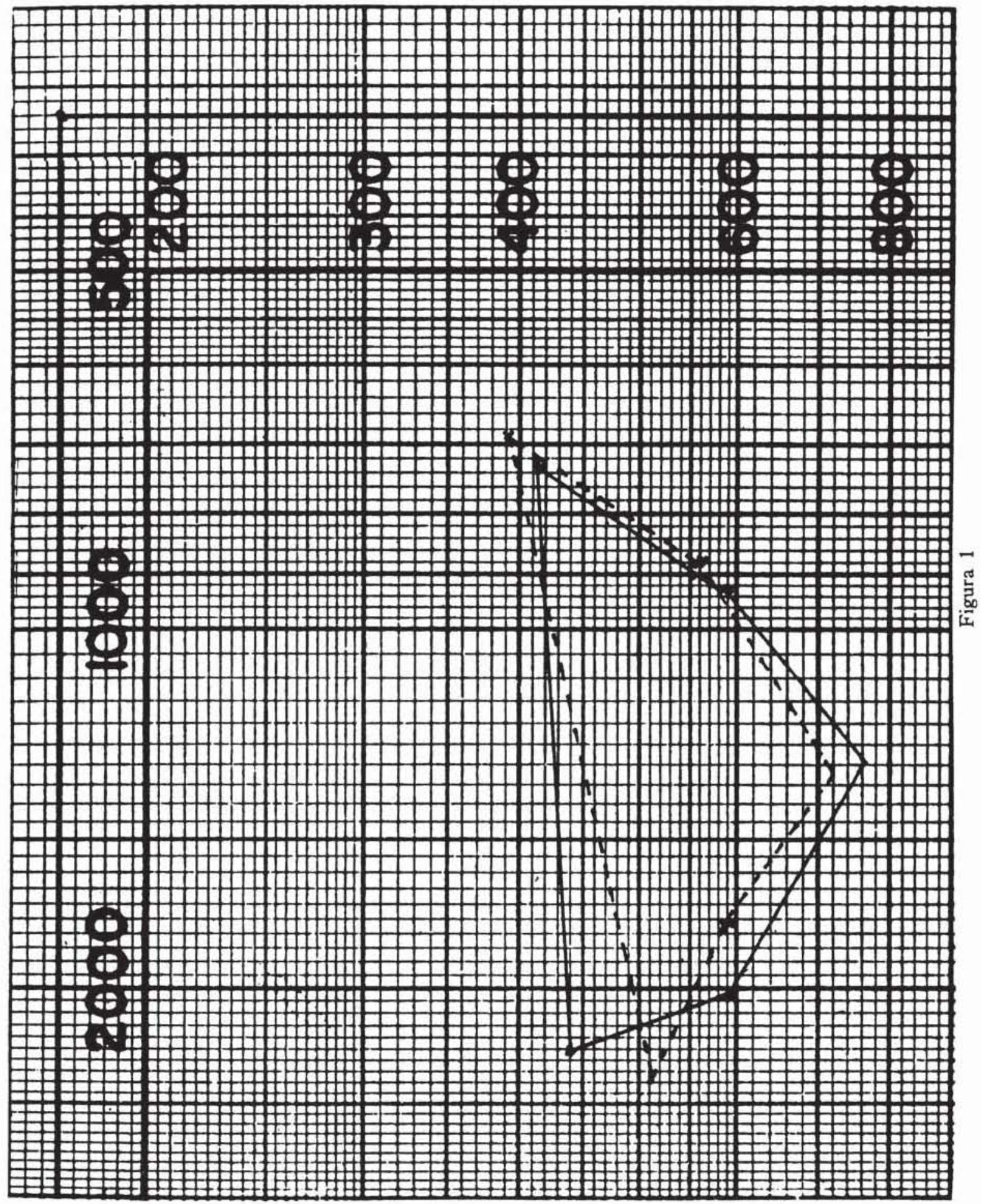

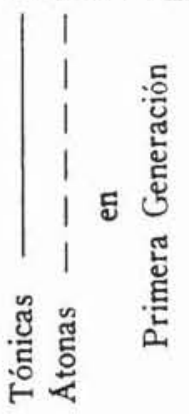

(c) Consejo Superior de Investigaciones Científicas

http://revistadefilologiaespañola.revistas.csic.es Licencia Creative Commons 3.0 España (by-nc) 

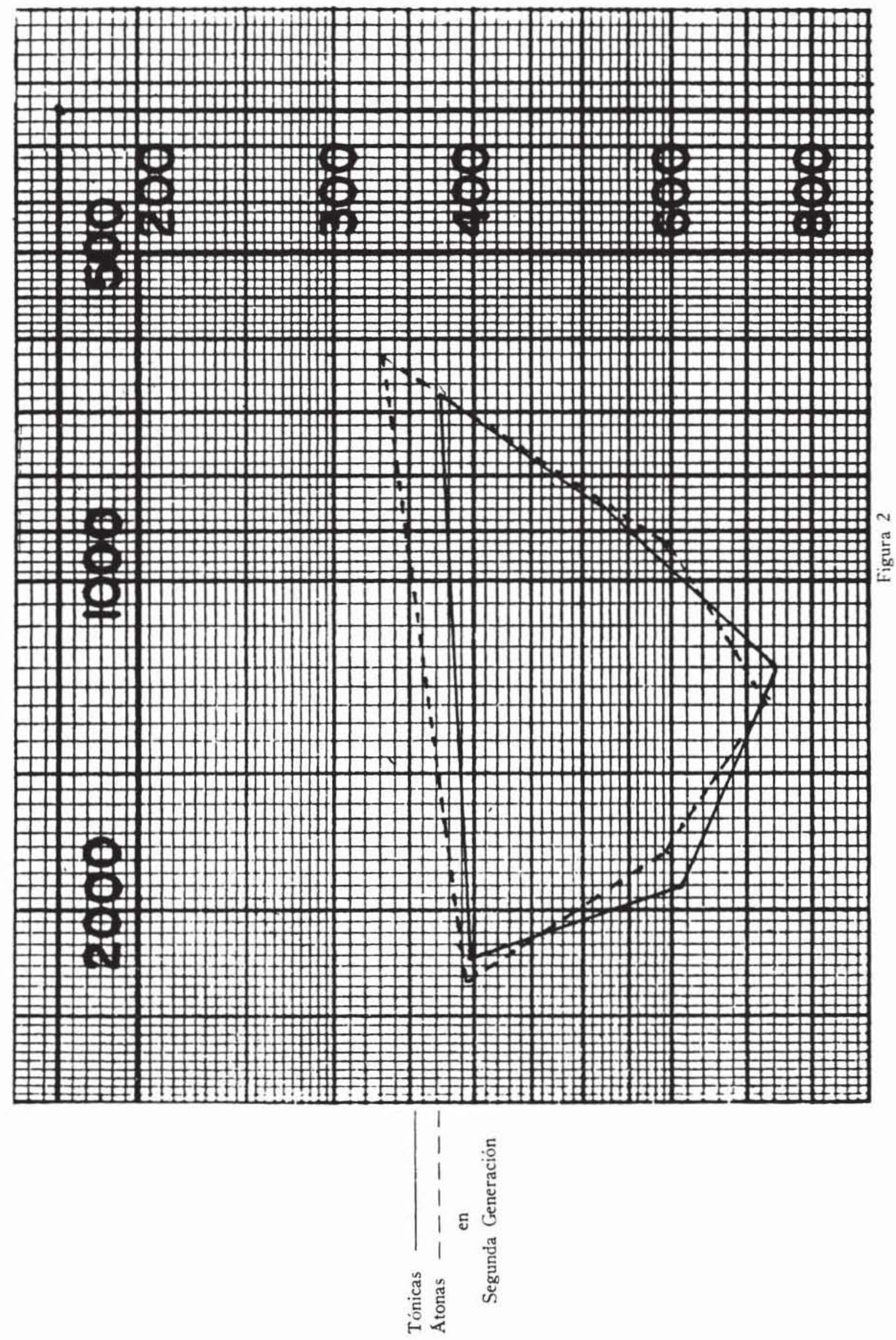


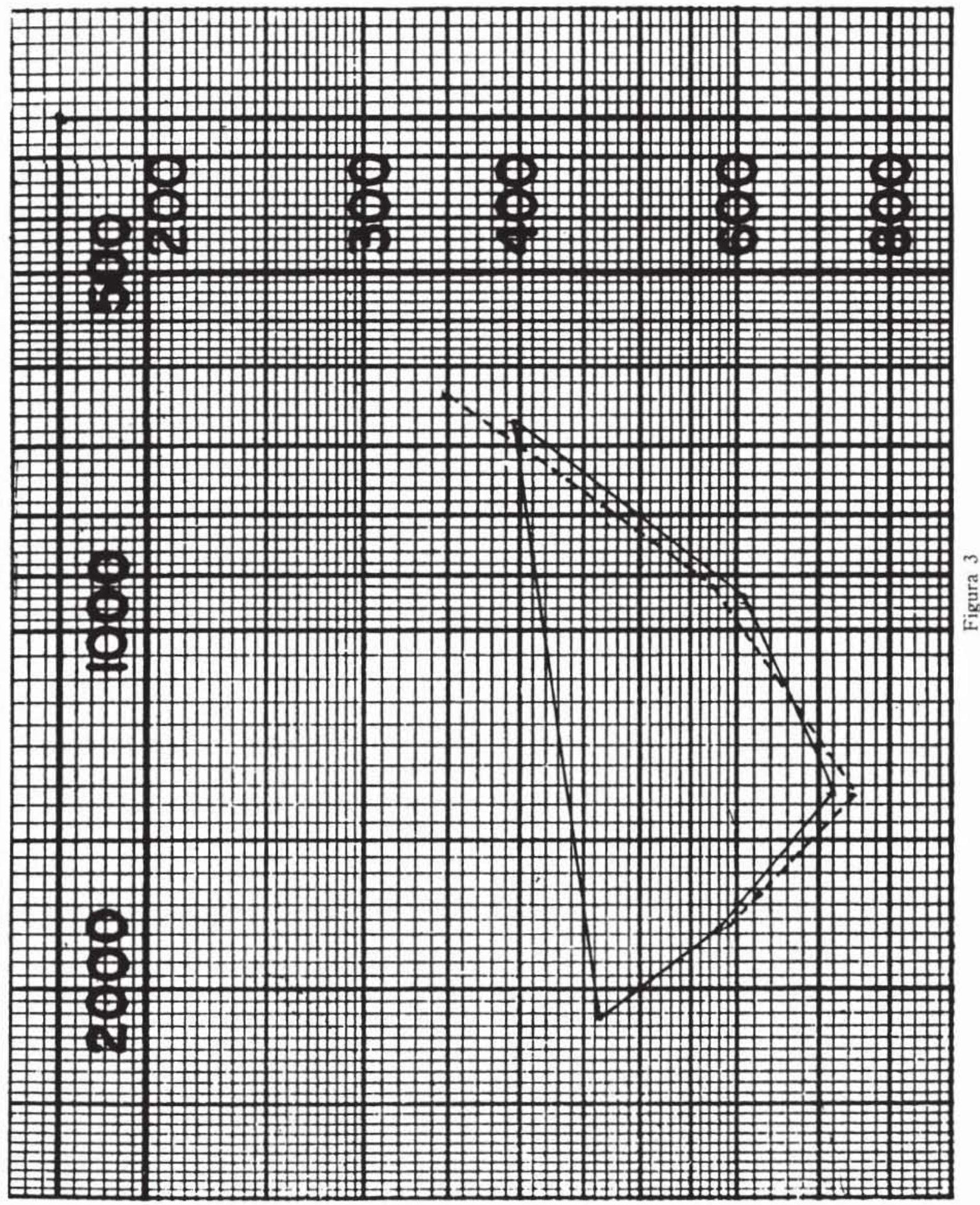

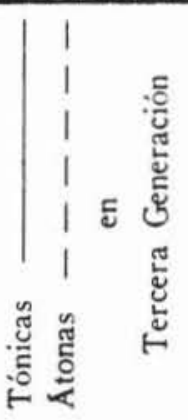




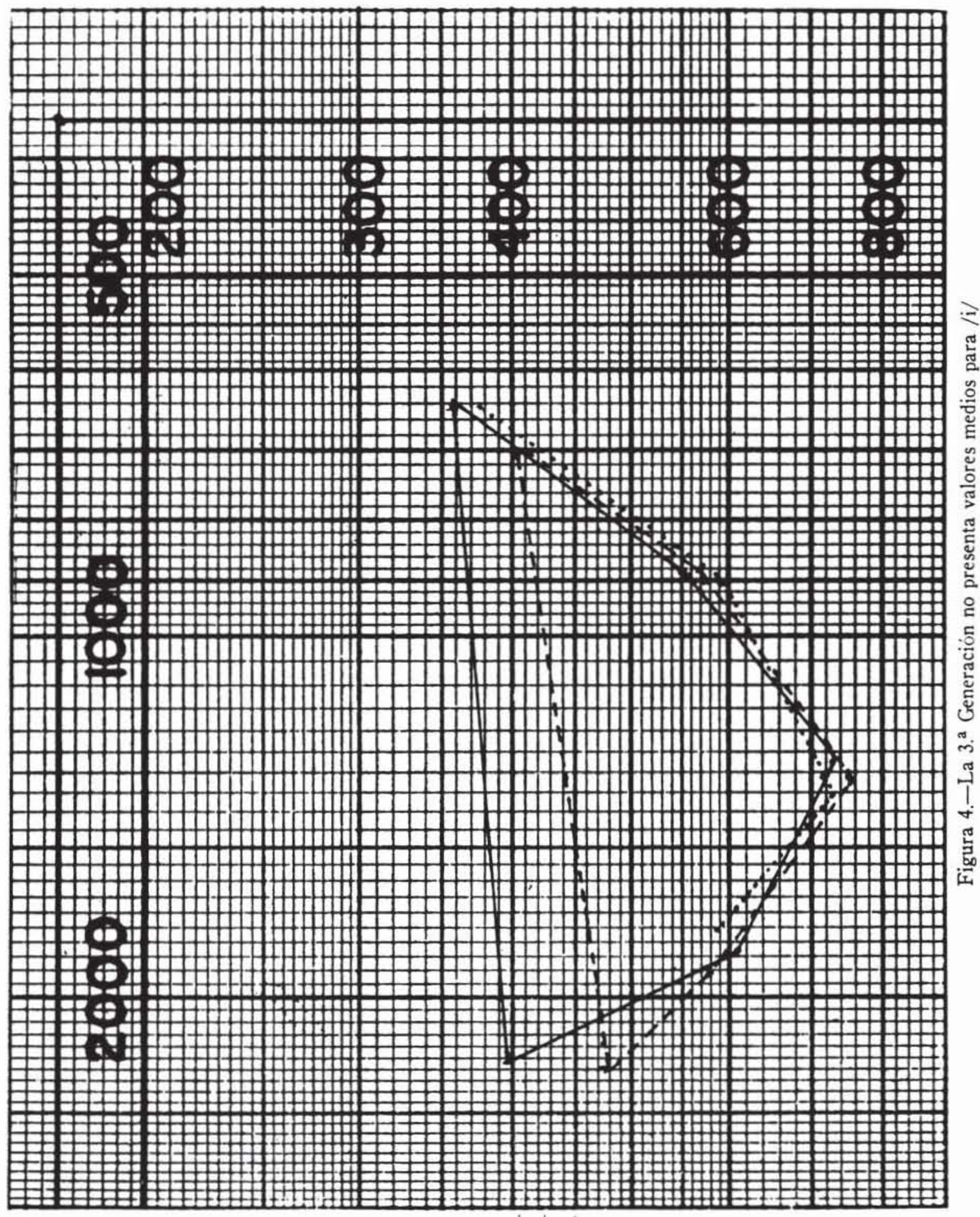

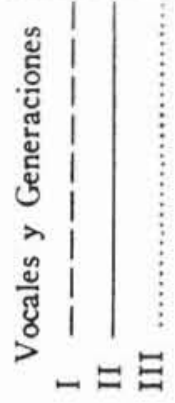




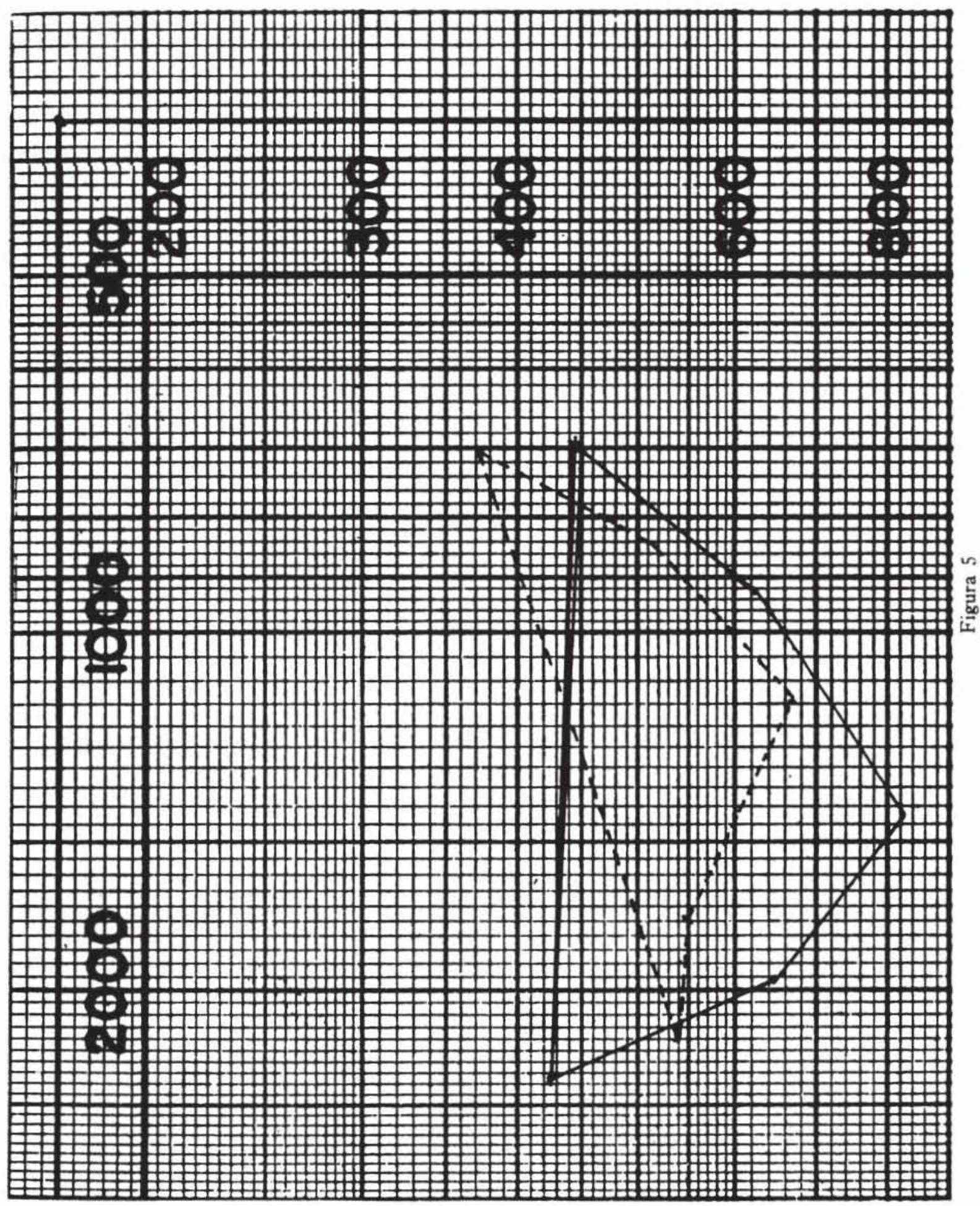

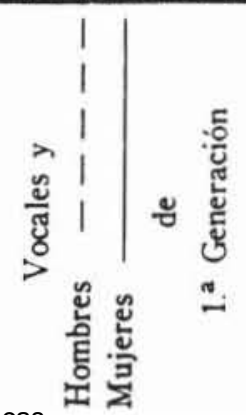




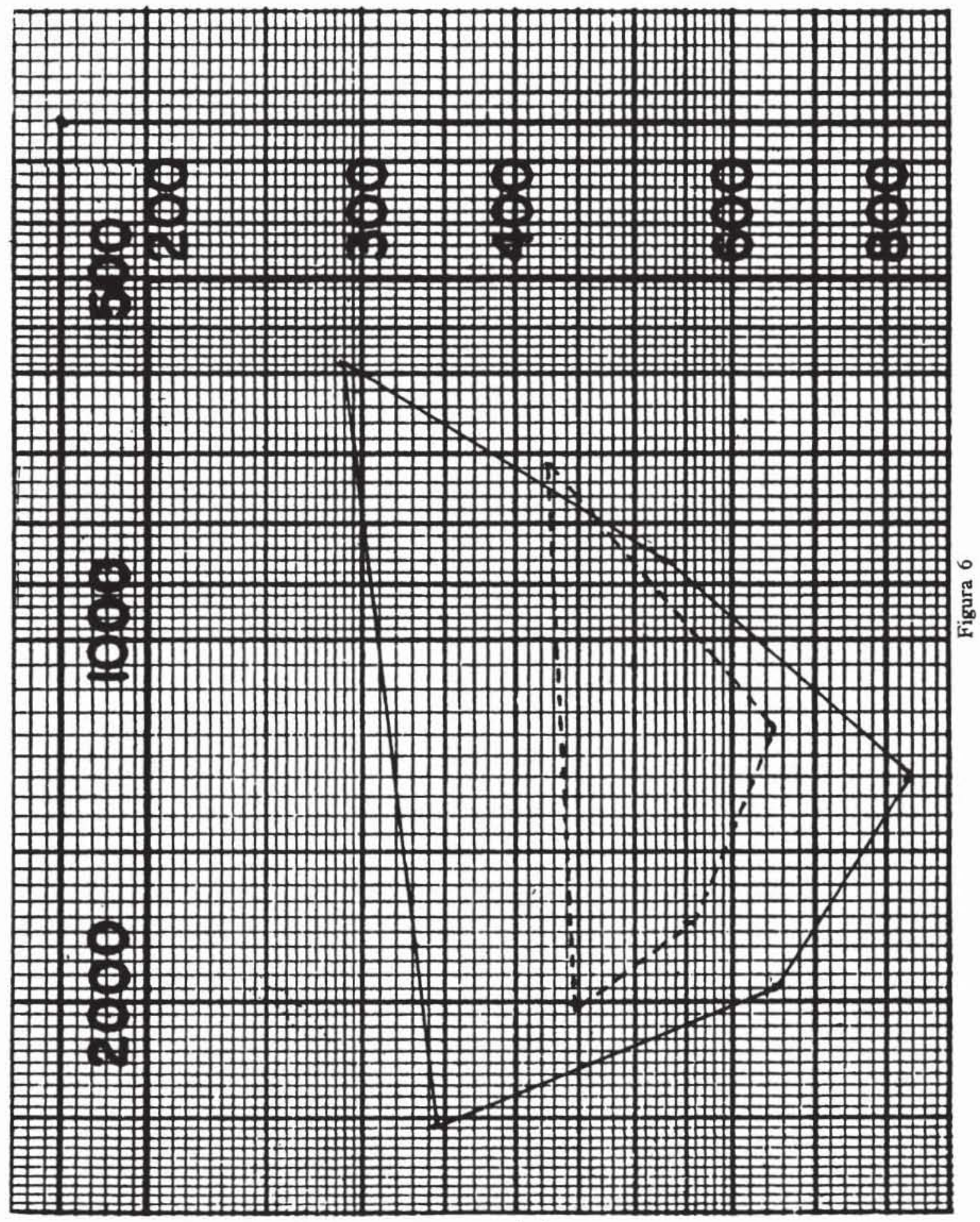

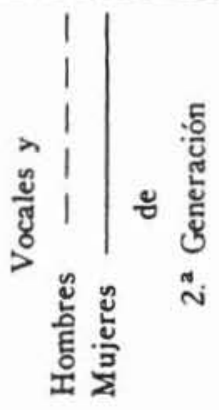




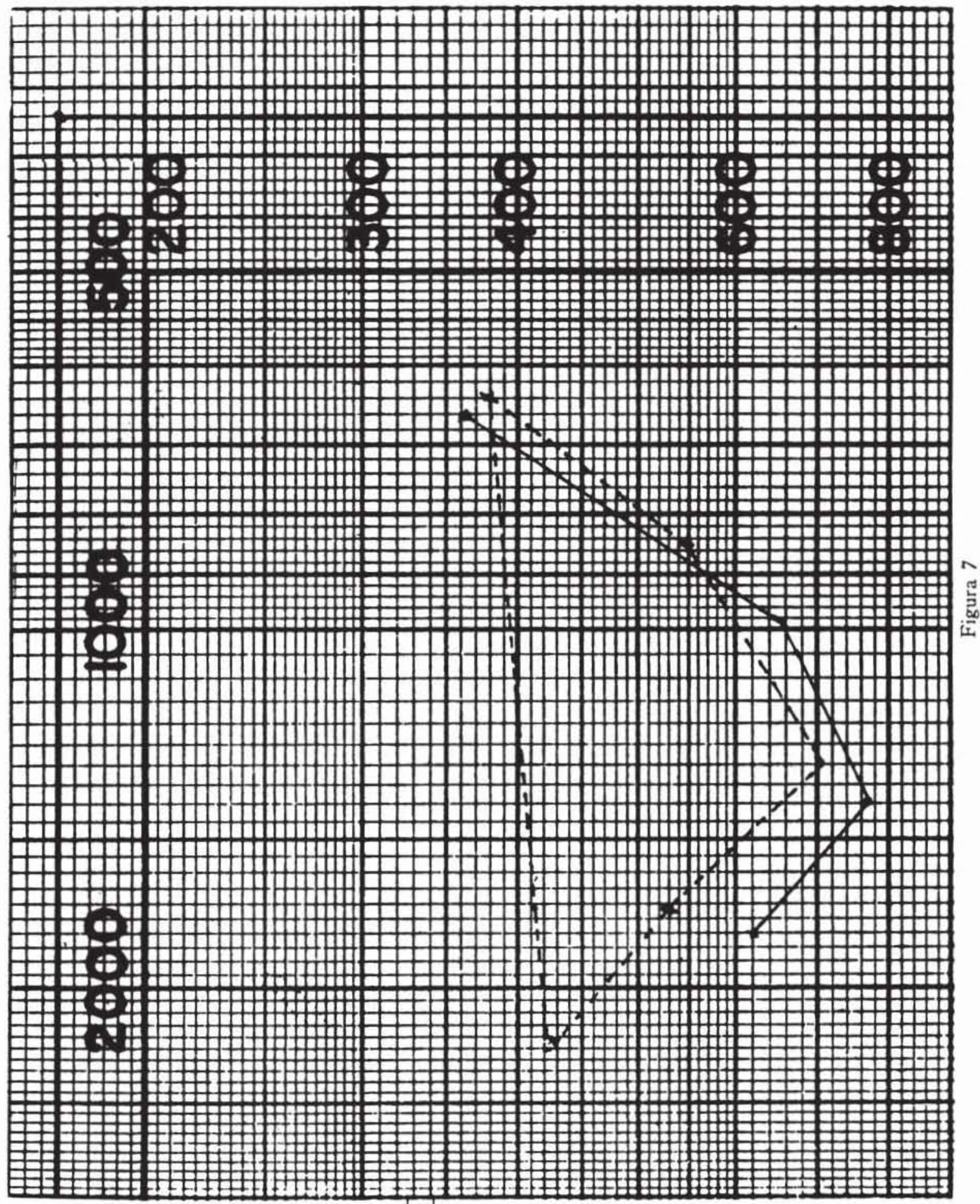

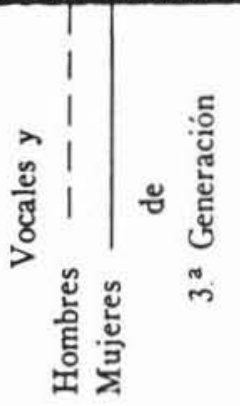




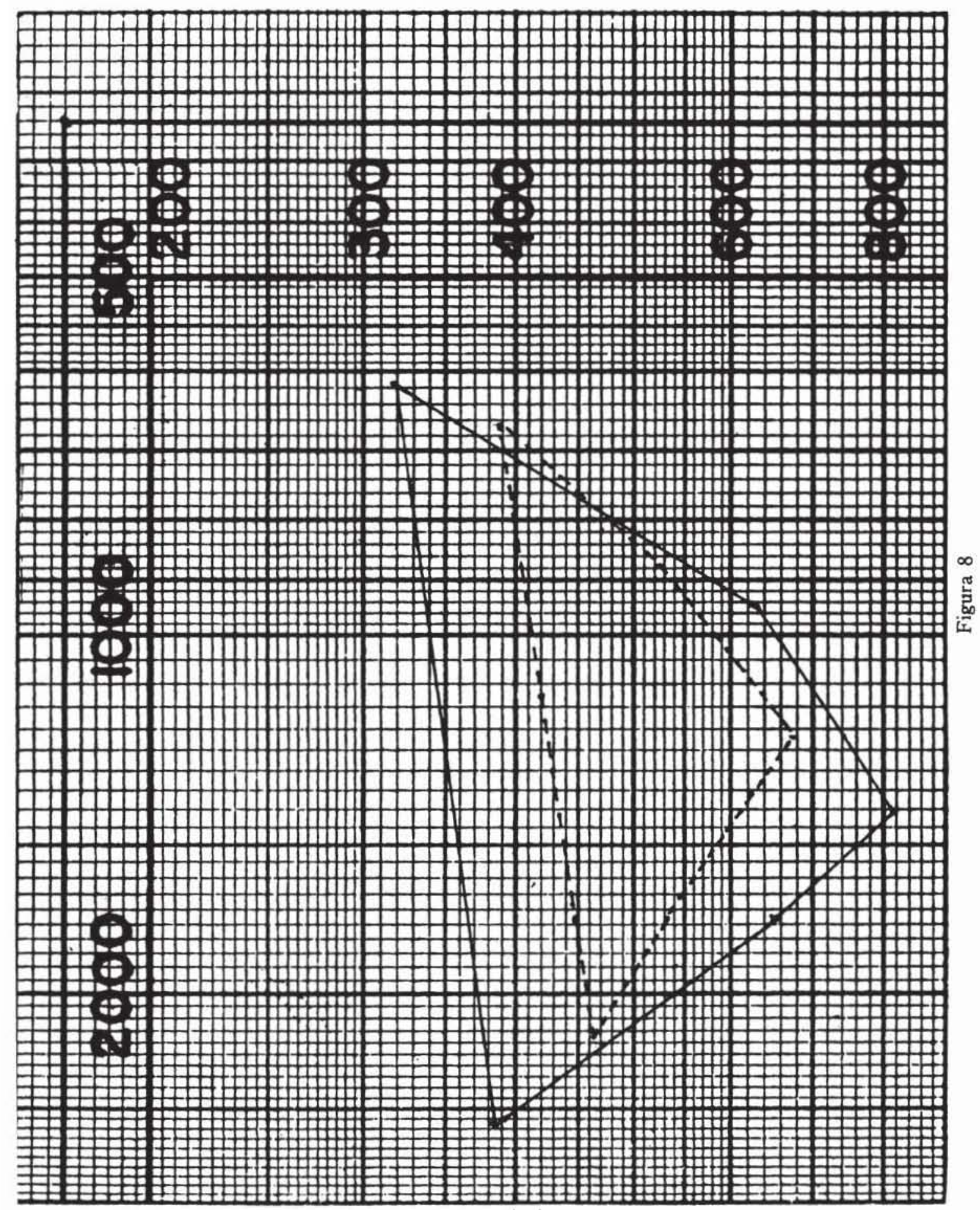

点

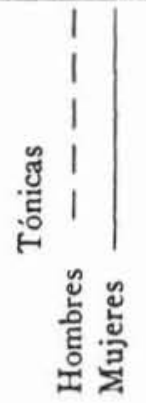

(c) Consejo Superior de Investigaciones Científicas

http://revistadefilologiaespañola.revistas.csic.es 


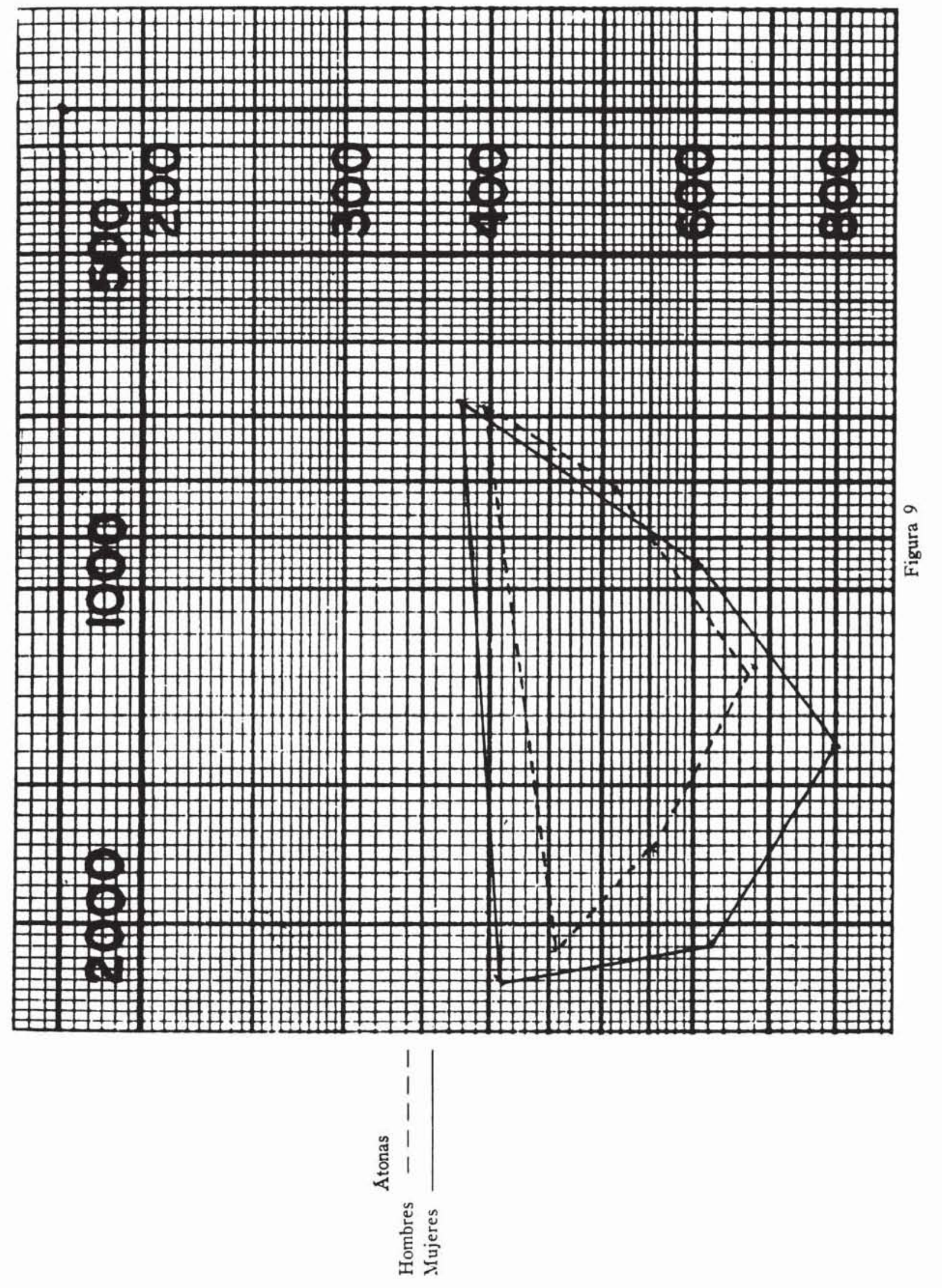




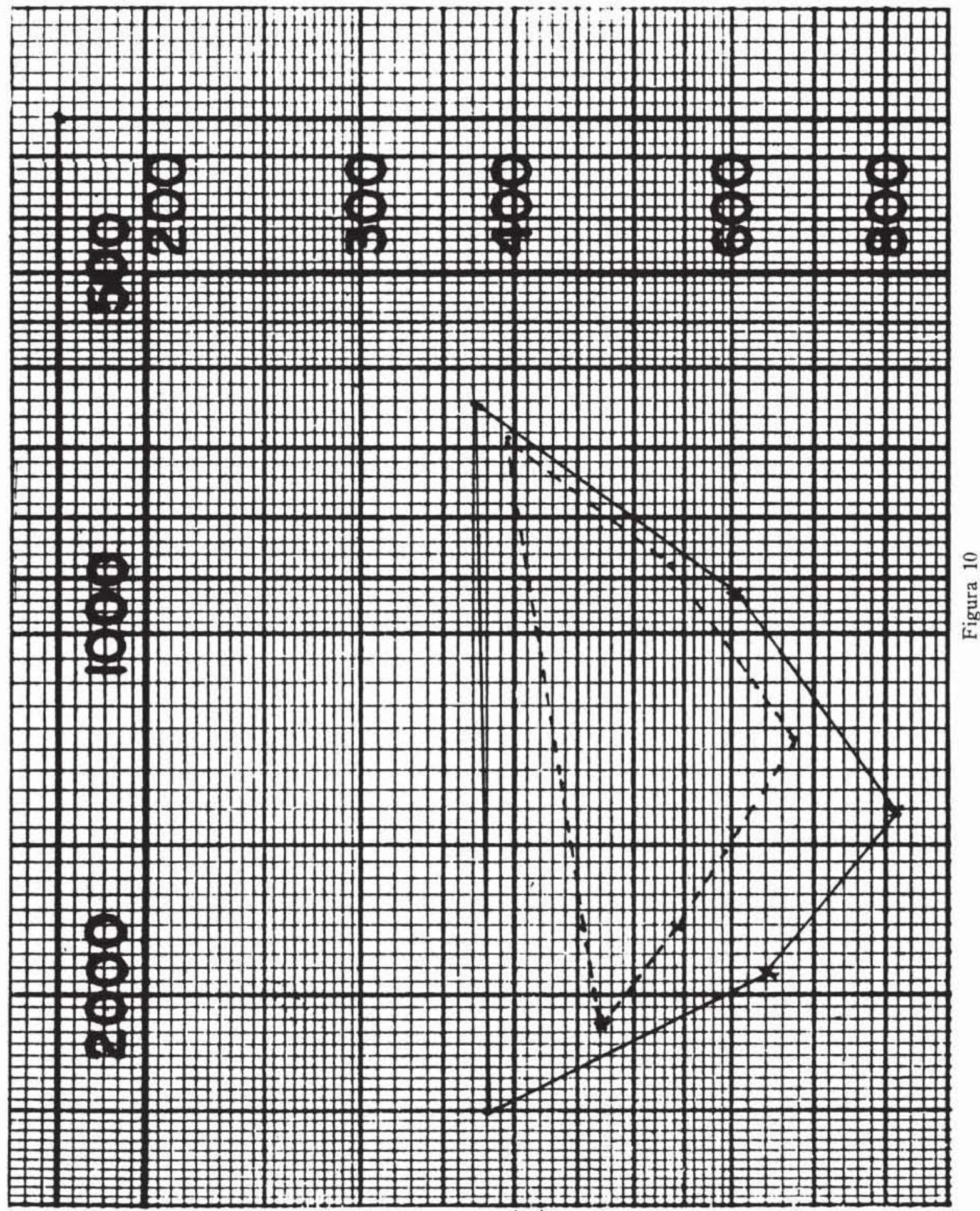

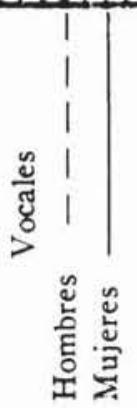

(c) Consejo Superior de Investigaciones Científicas Licencia Creative Commons 3.0 España (by-nc) 


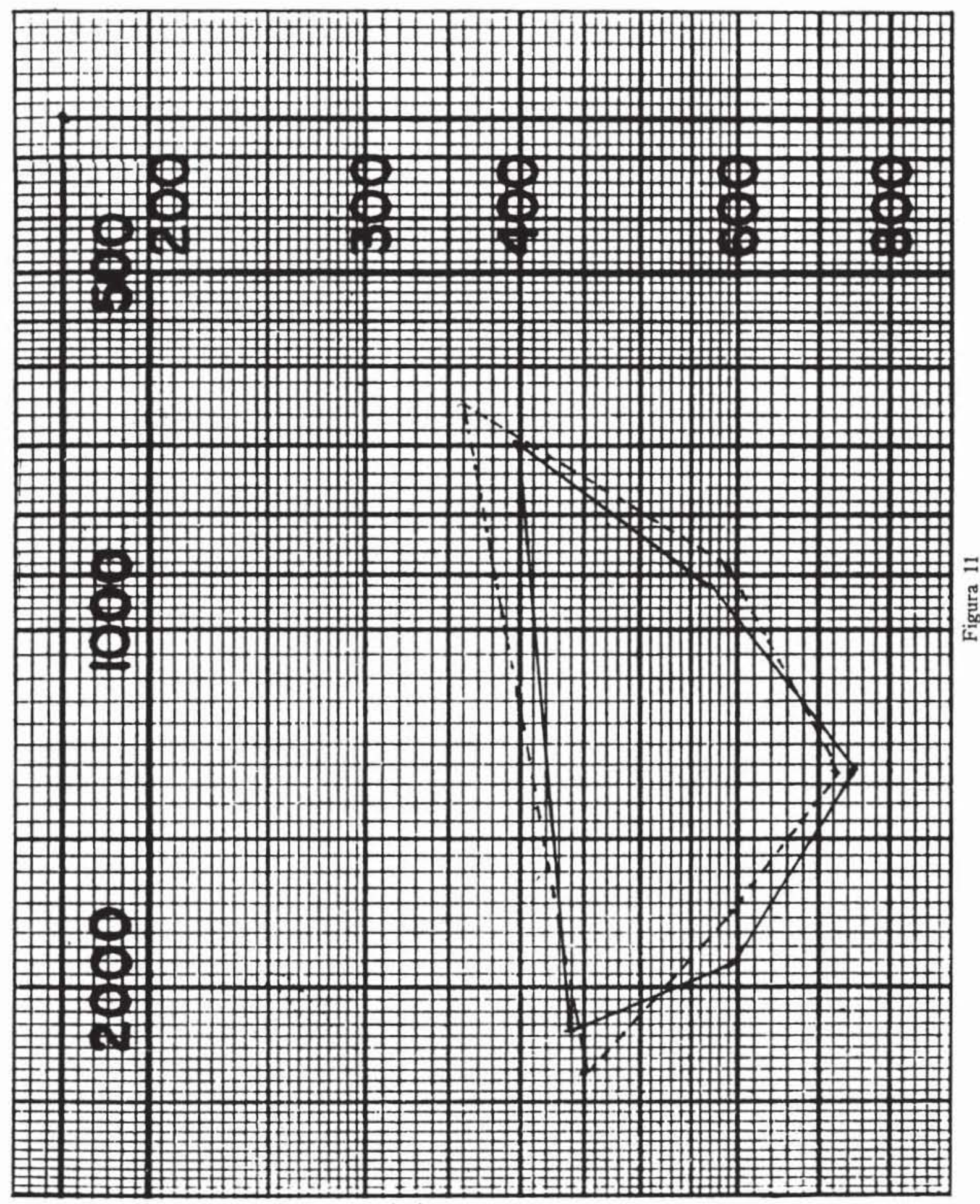

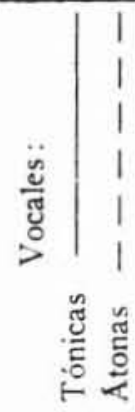




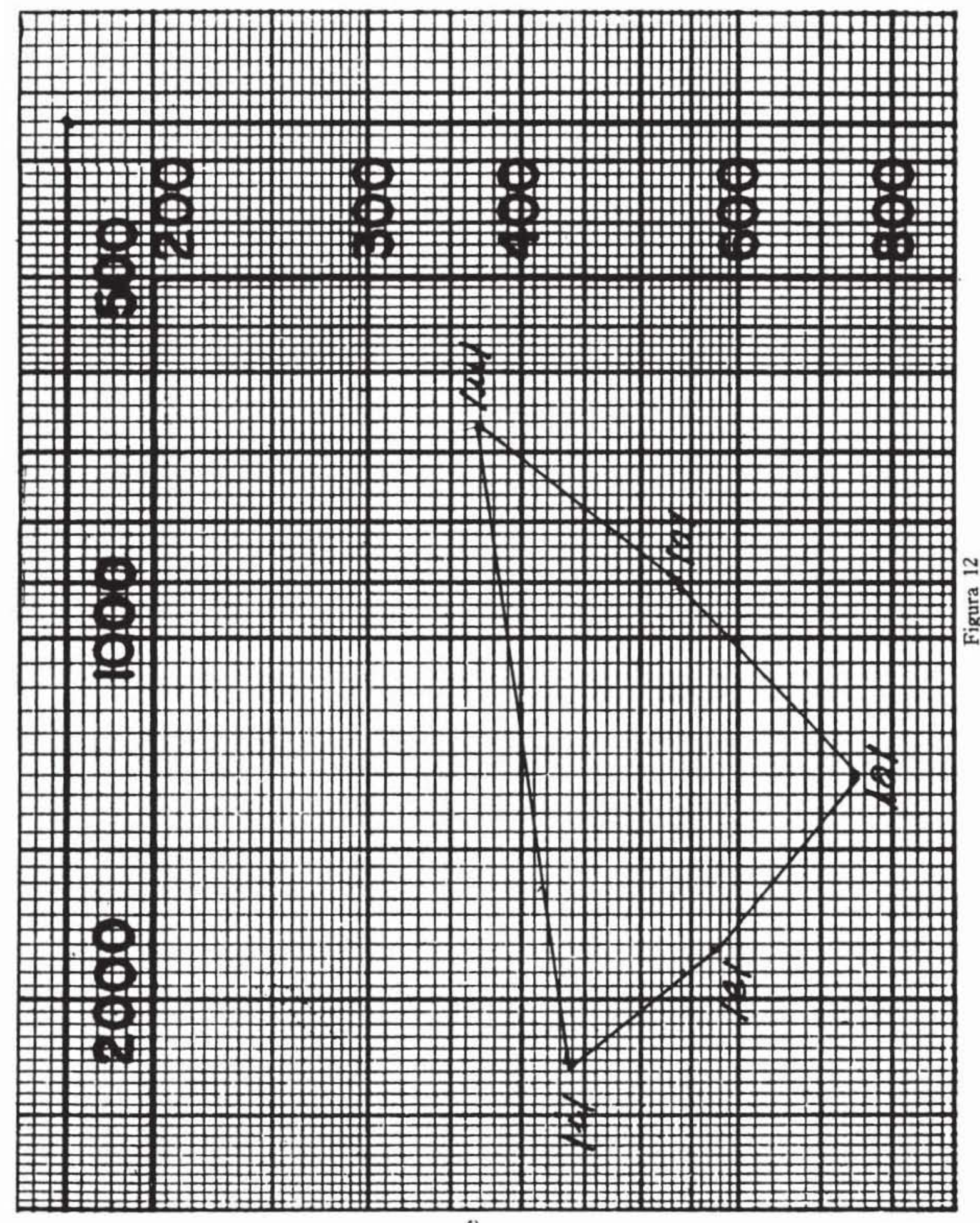

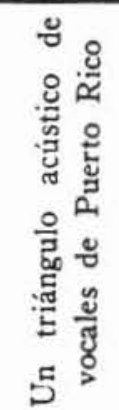

